\title{
Artigo
}

Resumo

Há uma diversidade de capacidades de apreensão cognitiva no ambiente escolar. Esta pesquisa privilegia o estudo da relação com o saber matemático. Um desafio maior aguarda o professor quando conseguir enxergar a questão da subjetividade, compondo o quadro de complexidade estampado na sala de aula. Optou-se neste estudo por uma metodologia de análise qualitativa dos dados obtidos por meio de questionários aplicados aos sujeitos estudados. Os resultados apontam a importância dada pelos alunos aos diferentes eventos vividos no ambiente escolar como determinantes de sua relação positiva ou negativa com o conbecimento matemático.

Descritores: subjetividade; professor do ensino médio; adolescentes; ensino de matemática.

\section{A RELAÇÃO COM O SABER E SUAS IMPLICAÇÕES NO DESEMPENHO ESCOLAR EM MATEMÁTICA}

\author{
Vilma Conceição da Silva \\ Francisco de Assis Moura
}

\section{Introdução}

$\mathbb{E}_{4}$ ste artigo é um relato de pesquisa sobre a relação com o saber matemático e suas implicações no desempenho em Matemática de adolescentes estudantes de escola pública de Minas Gerais. Discute-se aqui a necessidade de se considerar a influência de elementos subjetivos na aprendizagem da Matemática. Fica evidenciada a importância do afeto na construção de um campo favorável para apre-

\section{- Professora da rede Oficial do Ensino de Minas Gerais. Escola Estadual Dom Silvério - Mestre em Educação Matemática.}

- Universidade Federal de Ouro Preto - Instituto de Ciências Humanas e Sociais. Departamento de Educação - Professor de Psicologia. 
ensão do saber matemático, tornando-se possível estabelecer correlações entre a "transferência" e a "identificação" do aluno com o professor de Matemática. A afetividade pode ser inserida como importante instrumento de subjetivação do conhecimento matemático de modo que ele não se apresente para o aluno em sua dureza, facilitando a aprendizagem dos objetos matemáticos.

Serviram de subsídios nesta investigação os estudos de Bernard Charlot (2000), Maria Cristina Kupfer (2000), Leandro de Lajonquière (1992), Cabral (1998) e Silva (2008) e a psicanálise segundo Sigmund Freud. Estudos que levem em consideração elementos subjetivos no processo de aquisição de conhecimentos matemáti$\cos$ - que são de natureza objetiva e quantitativa - não são muito frequentes, portanto o que já foi pesquisado sobre o assunto é limitado. Fomos conduzidos a pautar nossa reflexão nos poucos trabalhos disponíveis sobre o tema, conforme está disponível nos subsídios teóricos abaixo.

A presente pesquisa propicia aos professores do Ensino Médio uma visão do aluno como sujeito desejante numa perspectiva psicanalítica e sua relação com o saber matemático. É notório que a prática docente se faz mediante muitos questionamentos. Assim, pode-se perguntar: o que leva um aluno a estar desmotivado desinteressado e apresentar-se preguiçoso aos olhos do professor de Matemática? A resposta está no desejo, uma falta instalada em algum momento da formação do psiquismo humano. O desejo, em psicanálise, representa "estar em falta" (Lajonquière, 1992, p. 156). Uma lacuna a ser preenchida. Esta falta é impossível de ser preenchida e funciona como uma mola propulsora obrigando o sujeito a estabelecer relações com o meio para aprender.

\section{Questão de Investigação}

Esta pesquisa surgiu de reflexões da pesquisadora e da comunidade escolar sobre o problema do desempenho desfavorável em Matemática dos alunos de Ensino Médio. A inquietação para investigar surge então, da experiência docente da pesquisadora no Ensino Médio, no meio estudantil e nas avaliações do rendimento nas escolas mineiras. Nessas reflexões verificou-se que os resultados dos alunos eram insatisfatórios, abaixo do esperado pelos professo- 
res e apontavam o problema como oriundo de diversos fatores. Os fatores apontados pelos professores se referiam à desconcentração, desmotivação, situação social adversa, problemas de codificação, desajustes emocionais, hiperatividade, dificuldades de fixação, baixo nível de percepção e sociabilidade. Além desses fatores havia, também, problemas referentes a método de estudo, grande número de alunos em sala de aula e de diferentes comportamentos, apatia, falta de acompanhamento psicológico na escola e falta de interesse de alguns pais de alunos em saber informações precisas sobre o regulamento interno da escola.

Esta investigação limitou-se a observar os fatores ligados ao sujeito-aluno, em sua desconcentração, desmotivação e desinteresse pelas aulas de Matemática. O que levaria um aluno a estar desmotivado, desconcentrado, desinteressado, apático, sem entusiasmo para o estudo e sem perspectivas? Todos estes fatores direcionam para o sujeito-aluno, para sua subjetividade e sua relação com o saber, ponto central desta investigação. Desta forma delineou-se como objeto desta pesquisa a relação com o saber e a subjetividade, almejando compreender a relação do aluno do Ensino Médio com o saber matemático veiculado pela escola com o interesse em descrever e entender as implicações de caráter subjetivo no desempenho escolar nesta disciplina. Optou-se pela metodologia qualitati- 


\section{Artigo}

va para análise e compreensão desse fenômeno ligado à aprendizagem.

$\mathrm{O}$ ambiente em que foi desenvolvida a pesquisa é uma escola pública estadual de ensino fundamental e médio, do município de Mariana, Minas Gerais. A escola localiza-se em um bairro central da cidade e atende a crianças, jovens e adultos, em seus três turnos, recebendo alunos residentes de diferentes bairros da cidade, além de atender aos distritos. A instituição atende a 209 crianças e a 1154 entre jovens e adultos que se distribuem pela manhã, tarde e noite. $\mathrm{O}$ número de alunos por classe varia de 35 a 40. A faixa etária dos alunos do ensino fundamental está entre 13 e 14 anos e do ensino médio, entre 15 e 19 anos. Alguns alunos extrapolam essa faixa, principalmente no noturno. Alguns alunos dependem do transporte escolar por residirem na zona rural. A maioria dos alunos é originária de famílias da classe média e de famílias de classe econômica menos favorecida. Possuem diversas necessidades materiais e vivem vários problemas de ordem afetiva ligados ao grupo familiar e social.

No intuito de identificar a relação que os alunos do Ensino Médio estabelecem com o saber matemático e a implicação desta no desempenho escolar em matemática, foi estabelecido o seguinte problema de investigação.

Que relação os alunos do Ensino Médio estabelecem com o saber matemático e qual a implicação desta 
relação no seu desempenho escolar em Matemática? Visando verificar a existência de uma conexão entre a relação com o saber matemático e o desempenho nesta disciplina, esta pesquisa foi focada nas "ações internas", ou seja, na subjetividade do sujeito, ou seja, no seu "desejo de aprender" ou "não" a Matemática, exteriorizada na forma de uma determinada relação com o saber matemático. O termo relação empregado neste contexto deve ser entendido como o estabelecimento ou não de um vínculo mediado pelo "desejo de aprender" ou "não aprender" o conteúdo apresentado.

Para a realização do trabalho de campo, os alunos foram inicialmente convidados a aderirem à pesquisa. Essa espontaneidade foi importante para que o foco da pesquisa não fosse prejudicado. Contou-se com a adesão de 17 alunos Esse grupo de 17 alunos do ensino médio está situado na faixa etária de 15 a 19 anos, exceção feita a uma aluna com idade de 35 anos, casada, e mãe de dois filhos adolescentes, que desejou participar da pesquisa. Os alunos são oriundos das três séries do ensino médio, sendo 3 alunos da $1^{\mathrm{a}}$ série, 9 alunos da $2^{\mathrm{a}}$ série e 5 alunos da $3^{\mathrm{a}}$ série. Seis deles são do sexo masculino e onze do sexo feminino.

Os dados foram coletados por meio de questionários semiestruturados e constituídos de questões fechadas e abertas com produção de textos escritos pelos participantes, relacionados com o cotidiano e com a vida escolar.

Para a coleta dos dados, foi proposto aos sujeitos da pesquisa responder a quatro questionários e compor textos. Procurou-se incorporar uma técnica de construção dos questionamentos de forma indireta para que, por meio das respostas dos alunos, se obtivesse um campo onde eles deixassem emergir sua subjetividade.

\section{Subsídios teóricos}

Observando os resultados do desempenho escolar em Matemática, tanto os das avaliações internas na instituição escolar quanto os das avaliações externas propostas pelo Sistema de Ensino Estadual e Federal, verifica-se que "algo" se interpõe além do cognitivo entre "o que se ensina" e "o que se aprende". O que se pode antecipar, do que é percebido intuitivamente no ambiente escolar, é que isto gera um estado de angústia tanto para o professor quanto para o aluno.

A busca por respostas levou a pesquisadora ao encontro de investigações realizadas pelo Professor Bernard Charlot e seu grupo de pesquisa sobre Educação, Socialização e Coletividades Locais - do departamento das Ciências da Educação da Universidade de Paris VIII, SaintDenis (ESCOL). Essa equipe iniciou este trabalho em 1987, na França. 
Atualmente, o Professor Bernard Charlot encontra-se no Brasil dando continuidade a este trabalho.

Charlot (2001) afirma que, para aprender, o sujeito empírico deverá antes estabelecer uma relação com o saber. Para ele essa questão é perceptível quando se constata que certos indivíduos, jovens ou adultos, têm desejo de aprender enquanto outros não manifestam esse mesmo desejo. Isso faz refletir e admitir, mesmo que hipoteticamente, que uma boa abordagem de conteúdos matemáticos seja condição necessária, mas não suficiente para o aluno apreender um objeto matemático. Que é necessário considerar a aprendizagem como dependente da relação que o aluno estabelece com o conhecimento em determinado momento de sua história escolar.

Uma reflexão sobre as relações estabelecidas dentro da sala de aula, quais sejam, as relações: aluno - conteúdo matemático - professor, e dos alunos com a escola poderão contribuir com condições mais favoráveis à aprendizagem da Matemática veiculada no Ensino Médio. A desvinculação com o conhecimento surge no cotidiano sob o disfarce da desmotivação, do desinteresse, da falta de atenção e da preguiça sendo estas posturas analisadas de forma superficial pela comunidade escolar. Para a pesquisadora esses fatores estão na ordem do desejo, da falta que mobiliza o ser e determina certa relação entre o aluno e o conhecimento matemático.

Procurou-se detectar a relação do aluno com saber matemático, em seu aspecto subjetivo, observando o aluno como sujeito desejante, sujeito do inconsciente, mobilizado pela necessidade de completar-se, de preencher a falta em si. Disto decorre nosso interesse pela análise do discurso numa perspectiva de orientação clínica psicanalítica. Esta metodologia clínica adotada permite identificar elementos expressos na forma escrita - ou oral - da organização do sujeito do inconsciente. $\mathrm{E}$ o fato de adotarmos a participação livre e espontânea não implicou em nenhum apriorismo da interpretação do fenômeno identificado. Partindo da metologia clínica procurou-se nas entrelinhas do discurso do aluno, captar sua subjetividade, seu desejo de aprender ou não a Matemática através da identificação de resíduos inconscientes (atos falhos, fugas, bloqueios) e sua relação com o outro, que é uma relação consigo mesmo. Ou seja, em seu desejo de aprender matemática, está inconscientemente, o sujeito desejante de relacionar-se com o outro, com o colega, com o professor de Matemática, com o mundo. O desejo de ser reconhecido no mundo, como humano. 


\section{Processos subjetivos presentes na aprendizagem}

Ao adotar o olhar da Psicanálise para compreender o processo de aprendizagem, Kupfer (2007) propõe que, antes de tudo, devemos buscar resposta para seguinte pergunta: o que se busca quando se quer aprender algo? Só a partir dela pode-se refletir sobre o que é o processo de aprendizagem, pois este depende da razão que motiva a busca de conhecimento. O processo de aprendizagem não poderá ter sua análise limitada aos aspectos cognitivos, considerando que sua dinâmica prende-se à constituição psíquica do aluno, de seu histórico de vida como sujeito socialmente constituído, inserido num contexto histórico-cultural, como sujeito desejante que se lança no mundo na busca incessante de encontrar respostas que o reintegre como ser. Encontra a instituição escolar como referência de um espaço cultural que poderá oferecer-lhe o objeto do conhecimento que ele acredita suprir sua falta. Nesse local, encontra outros sujeitos desejantes, colegas, professores. Integra-se em uma relação ou não com eles, dependendo do desejo que o move. O professor participante da educação escolar, também é um sujeito desejante, que deseja ou não estabelecer uma relação com o aluno oferecer-lhe ou não o objeto do conhecimento. Vendo dessa forma, o processo de aprendiza- 
gem revela-se submetido à clivagem inconsciente/consciente e com a dualidade subjetivo/objetivo. Participa-se desse jogo inconsciente, toda vez que se apresenta um novo objeto do conhecimento ao aluno. Uma demanda se faz por meio do desejo do professor de ensinar, mas é o aluno quem decide se vai se lançar no circuito desse desejo e quando assim o fizer, fará ao seu modo, com seu estilo, como sujeito do desejo. Estabelecerá certa relação com os colegas, com o professor, com a escola e com o saber que poderá ser-lhe favorável ou não na apreensão do conhecimento. Em resumo, quando o jovem adentra a escola há uma demanda que o solicita à aprendizagem, que compartilhe o conhecimento de sua cultura. Mas temse de considerar que todo sujeito solicita inconscientemente ao outro que, quando lhe peça algo, no seu pedido não se confundam demanda e desejo. Em outras palavras, responder à demanda do outro não deve acarretar o desaparecimento do demandado enquanto sujeito do desejo (Lajonquière, 1992, p. 184). Dessa forma, a subjetividade é parte considerável no processo de aprendizagem e considerá-la será condição preponderante para superarem-se as dificuldades de aprendizagem principalmente da aprendizagem Matemática.

\section{Da relação com o saber matemático}

Para compreender a relação que os alunos do Ensino Médio estabelecem com o saber matemático e quais as implicações disso no desempenho escolar em matemática, adotou-se a noção da relação com o saber segundo Charlot (2000). Para ele, na relação com o mundo, o homem só compartilha o que ele percebe, imagina, o que pensa desse mundo, por meio do seu desejo, como sujeito desejante. $\mathrm{O}$ mundo se apresenta para ele como um conjunto de significados, partilhados com outros homens. O homem, ao apropriar-se do saber, mergulha nesse universo de significados em busca de um significante que satisfaça seu desejo, que o complete. Desta forma, ele penetra neste universo simbólico onde se estabelecem as relações com o saber, que é relação com o outro, com o mundo e com a linguagem. Para apropriar-se do saber, o homem necessita se colocar em atividade no mundo, nesse universo simbólico. Precisa mobilizar-se para moldá-lo e transformá-lo. 
Charlot (2000, p. 80) apresenta várias definições de relação com o saber e informa que o "importante não é a definição "em forma" que se adota, mas, sim, a inserção do conceito de relação com o saber em uma rede de conceitos". Assim, adotou-se nesta investigação a seguinte definição: "A relação com o saber é o conjunto (organizado) das relações que um sujeito mantém com tudo quanto estiver relacionado com "o aprender" e o "saber" (ibid. 80)" e a relação com o saber matemático como o conjunto organizado das relações que o aluno mantém com tudo quanto estiver relacionado com "o aprender" e o saber matemático. Nesse contexto, consideraram-se importante analisar as relações família-escola no discurso do aluno, as relações do aluno com a escola, com os colegas, com os professores de matemática, com o conteúdo de matemática e procurou-se estabelecer uma correlação com o desempenho escolar em matemática. Segundo Cabral (1998), é necessário que se provoque o aluno para falar de modo que se relacione ativamente com o conhecimento, saindo de sua posição passiva e se mova no sentido de fixar compromisso de reelaborar seu modo de lidar com o saber institucionalizado. Para a autora, "O aluno deve retificar sua posição e assumir a responsabilidade na produção do conhecimento. De outro lado: o professor deve ocupar a posição de sustentar o trabalho do aluno a partir daquilo que este sabe e pode fazer"
(Cabral, 1998, p. 197). A pesquisadora Veleida Anahí da Silva (2008), em sua investigação sobre a relação com o saber na aprendizagem matemática, realizada com alunos de $1^{\mathrm{a}}$ a $5^{\mathrm{a}}$ séries, relata resultados importantes tais como: a relação com a Matemática da maioria dos alunos da $1^{\mathrm{a}}$ a $5^{\mathrm{a}}$ séries não se apresenta com a lógica do dom ou da carência sociocultural, mas, sim, com a lógica do estudo, do exercício intelectual e da mobilização do sujeito, ou seja, os que estudam obterão sucesso, os que não estudam, fracassarão. Considera-se que todos podem aprender Matemática, que a Matemática é importante, mas que é uma matéria difícil. Silva (2008) identificou que uma forte minoria de alunos - aproximadamente um terço pensa que nem todos podem ter êxito em Matemática, não tendo eles mesmos, uma cabeça matemática, demonstrando que, para um terço dos alunos, será necessário ocorrer uma mudança profunda na relação com a Matemática.

\section{Procedimentos metodoló- gicos}

Para a realização do trabalho de campo, os alunos foram inicialmente convidados a aderir à pesquisa. Essa espontaneidade foi importante para que o foco da pesquisa não fosse prejudicado. Ficou acordado com os 17 alunos selecionados naturalmente, 


\section{Artigo}

que responderiam às questões propostas, gradativamente, para evitar ansiedade e acúmulo de tarefas. Para esclarecimento aos alunos, a pesquisadora propôs realizar dois encontros semanais, que aconteceram as quartas e quintas-feiras, à tarde, durante três semanas. Assim, estaria disponível nesse período, de modo que poderiam responder as perguntas na sua presença ou em casa, como desejassem, e esclarecer suas dúvidas. Esta pesquisa foi aprovada pelo Comitê de Ética em Pesquisa da Universidade Federal de Ouro Preto.

Visando encontrar respostas para as indagações e minorar as inquietações relacionadas com o desempenho em Matemática dos alunos do ensino médio, propuseram-se várias questões e elaboraram-se situações estimulando o aluno a se expor e se posicionar de maneira que fosse possível através do registro de seu discurso perceber as relações que estabelecem com a Matemática, grafadas na linguagem inconsciente do sujeito, incorporadas em seu discurso, onde se procurou detectar o "desejo de aprender" ou "não" a Matemática, exteriorizada na forma de uma determinada relação com o saber matemático.

O primeiro questionário constituiu-se de questões fechadas acompanhadas de justificativas e duas questões totalmente abertas. Por meio dele, procurou-se resgatar uma parte da história da vida escolar do aluno mais relacionada com a Matemática, 
resgatando momentos das primeiras séries iniciais até o presente. Também, propuseram-se questões para captar as relações da família com a escola, do aluno com a Matemática, do aluno com os colegas, do aluno com o professor de Matemática. O segundo questionário foi composto de questões abertas direcionadas para detectar o valor e o sentido da vida e sua representação de Escola. Composto das seguintes questões: 1 . Descreva o que é importante na vida de um adulto? 2. O que a escola representa na vida de uma pessoa? 3. O que motiva os alunos virem à escola? 4 . O que você sabe e que a escola não ensina, mas que você julga importante para sua vida?5. O que você desejou e procuron aprender fora da escola, que você julga importante? Como você aprendeu?

O terceiro questionário foi composto de questões abertas direcionadas para detectar o valor e o sentido dos conteúdos matemáticos veiculados pela Escola. Seguem as questões utilizadas: 1. Qual a importância que você atribui aos conhecimentos matemáticos ensinados pela escola? 2. Quais são os conhecimentos matemáticos que você aprendeu na escola e que você utiliza no seu dia-a-dia? 2.1. Quais os conhecimentos matemáticos que você não utiliza no seu dia a dia? 3. Em sua opinião, o que é importante saber para se dar bem na vida? 4. Quais os conteúdos matemáticos aprendidos na escola que poderiam beneficiá-lo? 5. Para você quais são as utilidades dos conteúdos de matemática do ensino médio ensinados pela escola? 6. Em sua opinião, como podemos conseguir o engajamento dos alunos a atividade matemática tipicamente escolar?

O quarto questionário foi composto de duas questões abertas direcionadas para detectar os sentimentos, marcas e traços impressos em cada um no contato com o conteúdo matemático e nas aulas de Matemática. Elas foram propostas do seguinte modo: Tema 1: Sentimentos em relação a Matemática; Descreva em um pequeno texto, os sentimentos que surgem em seu intimo quando um novo conteúdo matemático lhe é apresentado. Tema 2: Momentos das aulas de matemática que marcaram minha vida; Procure se lembrar deste sentimento nas séries anteriores. Relate as situaçoes que ocorreram nas aulas de Matemática que marcaram sua vida.

O objetivo da pesquisa foi o de detectar a existência ou não de relações que os sujeitos estabelecem com o saber matemático. Uma vez verificada a existência de relações, identificar sua influência no desempenho escolar em Matemática.

Realizou-se levantamento de dados através de análise de documentos a fim de verificar o rendimento escolar dos alunos participantes. Utilizou-se este parâmetro como referência para análise da relação que estes alunos estabelecem com o saber matemático e 
suas implicações no seu desempenho escolar. Procurou-se relacionar esses dados e as informações obtidas qualitativamente nos questionários para orientar esta investigação e fornecer algumas respostas.

A análise dos dados visou detectar a subjetividade presente no discurso do aluno, almejando o sujeito do desejo e o seu comportamento perante situações que envolviam o conhecimento matemático. Em seguida realizou-se uma análise da relação com o saber dos 17 alunos e finalmente uma análise comparativa de modo a detectar a relação que estabelecia com o saber matemático e as implicações disso no seu desempenho escolar em Matemática.

\section{Análise de dados}

As primeiras análises levam-se crer estar perante o sujeito desejante, estampada na subjetividade presente no discurso. Para exemplificar, transcreveu-se parte dessa análise: Quando um novo conteúdo de matemática me é apresentado eu fico curioso para ver o que é,... $(A 23 C)$. $\mathrm{O}$ aluno se predispõe à recepção de novos significantes, condicionado à postura do professor, daquele que ocupa a posição do Ideal. mas depende do professor que me apresenta, pois meu último professor (do $3^{\circ}$ ano) quando apresentava algo novo dava até um certo receio, pois era mais uma oportunidade de ser destratado se alguma pergunta fosse fei- ta, pois ele diria que já havia ensinado aquilo e gritava com os alunos. (A23C). Observa-se que o aluno coloca em evidência que o desejo de aprender está diretamente afetado pela não existência de um campo favorável de aprendizagem onde possa ser estabelecida relação positiva de identificação talvez do aluno com o professor, o que facilitaria, segundo o entendimento da pesquisadora, a apreensão de novos significantes. Todavia, é possível deduzir daí que a vicissitude a ser enfrentada está no campo da relação com o professor repercutindo na relação com o saber matemático. Determinados alunos se veem em uma rede de emaranhados em que nenhuma saída possível se apresenta, pois, ressentem de dificuldades anteriores no conteúdo. Para o aluno: É estranho pensar nisso, porque, para mim, o que ocorre, várias vezes, é a dúvida em uma matéria que acaba me atrasando e, assim, impedindo o entendimento para a próxima matéria. (A13C).

$\mathrm{O}$ aluno (A13C) posiciona-se como espectador, observando sua deficiente rede de significantes, sem mobilizar-se para alterar a situação atual, o que certamente influenciará em sua aprendizagem, caso não reconsidere sua postura. [...] Sinto como se a "bola de neve aumentasse" cada ver. mais e, assim, atraindo um pequeno desespero. (A13C). Nota-se, a presença do sujeito desejante em seu conflito subjetivo perante o conhecimento matemático. É nesse ambiente subjetivo que está inserida esta investigação. 
Baseando-se na definição da relação com o saber matemático adotada nessa pesquisa e ao analisar o conjunto dos 17 alunos, observou-se que a relação com o saber matemático dos mesmos, se mantém na relação que a família estabelece com a escola e repassa ao aluno. Isto pode ser constatado, por exemplo, no relato do aluno (A13E): Eles acham (e têm raz̃ão) que o estudo é fundamental para o meu futuro; por isso me diz̧iam para estudar (A13E). Ou na relação do aluno com os colegas e com a escola, conforme relata A23B: Em primeiro lugar o ambiente escolar; as amizades, as brincadeiras, as risadas, etc. Em segundo lugar, a necessidade de saber mais para crescer na sociedade. Existe a necessidade de saber dividir a hora de descontração e a hora de absorver conhecimento. O que vimos nas escolas é que os alunos buscam muito em horário de aula. Falta um pouco de educaşão vinda de casa (A23B).

Dessa forma, o saber matemático também está sustentado inicialmente nesse tripé, mas para se efetivar deverá se sustentar na relação com o professor e com o conteúdo matemático veiculado pela escola. Percebe-se que a relação com o saber matemático enfrenta maiores vicissitudes no campo da relação do aluno com o professor e no campo de relação do aluno com o conteúdo matemático do Ensino Médio, pois este se apresenta para o aluno como difícil e desprovido de valor, mas ao mesmo tempo ele é interessante. Apesar das vicissitudes, pode-se dizer que grande parte dos alunos tende a gostar da Matemática. E gostar de Matemática é um fator subjetivo que favorece o desempenho nesta disciplina.

Para ilustrar essa análise, buscou-se identificar as facilidades e as dificuldades dos alunos em relação aos conhecimentos matemáticos veiculados na escola. Da análise dos resultados, observou-se que a partir da $5^{a}$ série os alunos passam a ressentir mais dificuldade em assimilar o conteúdo matemático. Esse aumento da dificuldade tende a contribuir para diminuição do gosto pela Matemática. Mas, também, há alunos que alegam ter facilidade com a Matemática e não gostam. Isso demonstra que o fato de ter facilidade não faz o aluno sentir prazer com a atividade matemática. São situações peculiares como essas que provam a presença do sujeito desejante e da subjetividade, manifestada na relação com o saber matemático. Algumas explicações dos alunos sobre as dificuldades de aprendizagem em Matemática apontam para problemas na relação com o professor ou o fato de não gostar de Matemática, ou ainda de não ter interesse ou atenção nos momentos de aula. Para alguns alunos, a facilidade em lidar com o conteúdo matemático está no fato de 


\section{Artigo}

gostar de Matemática, mas há relatos de alunos que têm facilidade e não gostam de matemática. Outras explicações dos alunos sobre a dificuldade que encontram para compreender o conteúdo matemático estão ligadas, segundo eles, ao fato de lidarem com um conteúdo mais complexo, comparado ao conteúdo do Ensino Fundamental. Que muitas vezes ressentem da falta de conhecimentos das séries anteriores e que a atividade matemática exige esforço mental.

Finalmente, percebeu-se o sentido dado à importância do conhecimento matemático no contexto escolar. A resposta dos alunos levou-nos a concluir que os conteúdos do Ensino Médio são tratados como bens culturais que serão utilizados no futuro pelo aluno como ponte para a graduação ou curso técnico, para trabalhar; ou, em outra perspectiva, não possuem nenhuma utilidade. Os conteúdos matemáticos valorizados pelos alunos foram os conhecimentos adquiridos nas séries anteriores, ou seja, as operações básicas, alguns raros conhecimentos do Ensino Fundamental e Médio, como porcentagem e estudo de gráficos.

O fato do aluno do Ensino Médio não atribuir um sentido e um valor aos conteúdos matemáticos desse nível faz com que ele trate esses conteúdos como uma atividade puramente escolar, desperdiçando o melhor tempo de sua aprendizagem. Já mais próximos de concluir sua formação básica, os alunos pensam mais na es- 
tabilidade financeira, na independência, na conquista da liberdade. Esses desejos podem mobilizá-los para aprender Matemática visando uma aprovação na universidade ou em curso técnico. Foi possível perceber esse desejo no discurso dos alunos.

Enfim, percebe-se que a totalidade dos alunos considera que os conteúdos matemáticos ensinados no Ensino Médio não são utilizados no cotidiano. Por este motivo não se mobilizam para compreendê-los. $\mathrm{O}$ aluno não percebe esses conhecimentos como base da cultura, como uma linguagem científica e, dessa forma, ele não percebe seu sentido nem seu valor como bem cultural. Trata-o simplesmente como um objeto escolar que, talvez, terá certa utilidade posteriormente. Como seu valor pode ser adiado, inconscientemente, ele poderá adiar sua aprendizagem desperdiçando seu tempo escolar.

Ao realizar análise comparativa da relação do aluno com o saber matemático e fazer correlação com o desempenho, pode-se observar que os alunos propensos a ter desempenho situado na média ou abaixo do esperado são alunos que, frequentemente, têm dificuldades na relação com o professor, e/ou com o conteúdo matemático. Observa-se que, quando o aluno possui uma relação positiva ou uma relação oscilante com o professor, ou seja, que pode passar de negativa para positiva e vice-versa e uma relação negativa com o conteúdo matemático, é possível que possa encontrar um sentido e, movido por um desejo, poderá superar suas vicissitudes em relação ao conteúdo, obtendo um desempenho acima do esperado. Contudo, destacamos: para os alunos que alegam ter dificuldade para aprender Matemática, mas que, apesar disso continuam gostando da Matemática, possuem mais possibilidade de vencer a resistência oferecida pelo objeto matemático e ter um desempenho favorável. Para os alunos que somam relações positivas e/ou oscilantes com o professor e o conteúdo, geralmente, obtém desempenho acima do esperado. Dessa forma, percebe-se na análise do conjunto que, dependendo da relação que o aluno estabelece com o saber matemático, poderá haver uma implicação positiva ou negativa em seu desempenho. Devido aos fatores subjetivos detectados na pesquisa, acredita-se que os valores de desempenho das avaliações quantitativas, promovidas pela escola ou pelo sistema de ensino, estão mais próximos de demonstrarem a relação que o aluno estabelece com o saber matemático do que demonstrar a aprendizagem em Matemática. Como as avaliações externas de desempe- 
nho procuram medir domínio de habilidades e competências em Matemática, é compreensível, no momento, que os níveis de desempenho em Matemática nessas avaliações estejam abaixo do esperado. Acredita-se que, para alterar esse quadro, será necessário encontrar uma forma de alterar a relação do aluno com o saber matemático.

\section{Considerações finais}

Apoiou-se no pensamento psicanalítico e na relação com o saber para obter os dados e analisá-los. Recorremos ao "método clínico" para analisar o discurso dos alunos enquanto sujeito desejante atrevendo-se a perseguir o "fantasma" de cada um na manifestação de sua subjetividade e sua consequente relação com o real social.

Das análises feitas, considerando os aspectos subjetivos dos discursos, percebemos que a relação positiva do aluno com o saber matemático apóia-se na relação que estabelece com a família, com os colegas e com a escola. Por outro lado, as maiores dificuldades enfrentadas pelos alunos se estabelecem na relação com o professor de Matemática e com o conteúdo matemático.

Destaca-se que a relação dos alunos com o saber matemático é puramente institucional. A matemática aparece como um obstáculo a ser transposto e não necessariamente como um conhecimento que deve ser assimilado e compartilhado em seu aspecto cultural. Os aspectos subjetivos podem explicar o que o aluno relata sobre a dificuldade de aprender matemática, apontando para a dureza relativa em que se apresenta o objeto matemático para ele e do esforço empreendido para "digeri-lo". Já as implicações da subjetividade no desempenho ocorrem com maior frequência no campo da relação do aluno com o professor e no campo da relação do aluno com o conteúdo matemático. Esses resultados nos levaram a uma reflexão sobre a necessidade de incorporação da subjetividade à didática da Matemática. 
RELATION TO KNOW AND ITS IMPLICATIONS IN MATHEMATICAL SCHOOL PERFORMANCE

\section{Abstract}

The diversity of Qualitative cognitive abilities of apprehension appears as a complicating factor for the public school mathematics teacher, the greatest challenge awaits when you can see the issue of subjectivity which is the subject student and comprise a complex of print in the classroom. The mathematics teacher committed to its activity, which is uncomfortable with the unfavorable results obtained, you can get in the fields of relationship to knowledge, psychoanalysis, and bence the field of subjectivity and complexity that make up. It was chosen for this study a method of qualitative analysis of data obtained through questionnaires given to subjects. The results show the importance given by students to the various events experienced in the school environment as critical to their positive or negative relationship with mathematical knowledge. In conclusion, this study breaks with the positivist idea that learning and teaching are intimately linked, highlighting the subjective phenomena of the educational process.

Index terms: subjectivity; mathematics educations; high school teachers; adolescents.

RALACIÓN CON EL CONOCIMIENTO Y SUAS CONSECUENCIAS PARA EL RENDIMIENTO ESCOLAR EN MATE$M A T I C A S$

\section{RESUMEN}

Hay una variedad de habilidades cognitivas de aprebensión en el ámbito escolar que aparece como un complejo factor en el proceso de la enseñanza para el profesor de matemáticas de la escuela pública. Esta investigación se centra en el estudio de la relación con el conocimiento matemático. Un desafío más grande le espera a la profesora si podía ver el tema de la subjetividad, que forma el marco de la complejidad sellado en el salón de clases. Fue elegido para este estudio una metodologia para el análisis de datos cualitativos obtenidos a través de entrevistas con los sujetos. Los resultados indican la

458 Estilos da Clínica, 2011, 16(2), 442-459 


\section{Artigo}

importancia que otorgan los estudiantes a los diferentes eventos vividos en el ámbito escolar como factores determinantes de su relación positiva o negativa con los conocimientos matemáticos.

Palabras clave: subjetividad; enseñanza de las matemáticas; maestros de enseñanza media; adolescentes.

\section{REFEREANCIAS}

Cabral, T. C. B. (1998).Contribuições da psicanálise à educação matemática: a lógica da intervenção nos processos de aprendizagem. Tese de Doutorado, Faculdade de Educação, Universidade de São Paulo, São Paulo.

Charlot, B. (2000). Da relação com o saber: elementos para uma teoria (B. Magne, trad.). Porto Alegre: Artmed.

Charlot, B. (2001). Os jovens e o saber: perspectivas mundiais. (F. Murad, trad.). Porto Alegre: Artmed.

Kupfer, M. C. (2000). Educação para o futuro: psicanálise e educação. São Paulo: Escuta.

Kupfer, M. C. (2007). Freud e a educação: o mestre do impossivel. São Paulo: Scipione.

Lajonquière, L. (1992). De Piaget a Freud: para repensar as aprendizagens. A (psico) pedagogia entre o conbecimento e o saber. Petrópolis, RJ: Vozes.

Silva, V. A. (2008, janeiro/abril) Relação com o saber na aprendizagem matemática: uma contribuição para a reflexão didática sobre as práticas educativas. Revista Brasileira de Educação, 13 (37), 150-161. 